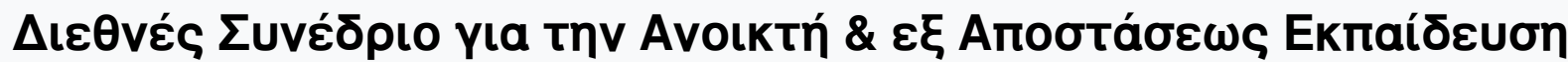

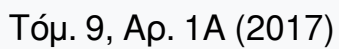

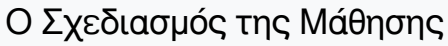

\section{Tónos 1, Mépos A}

\section{Практіка́}

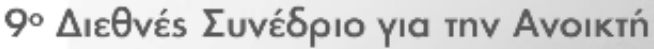

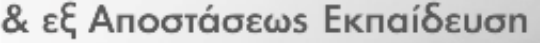

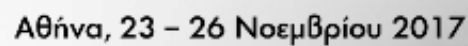

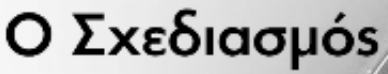 ins MáӨnons}

Enıนédeıa

Avióvns Aıvapákns

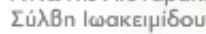

Mapia Niápn

Гке́̉n Mavoúoou

Tóvia Xaproqúৗara

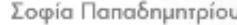

Avva Anoorodíovio

ISBN 978-618-82258-6.2

ISBN SET 978-618-82258-5-5

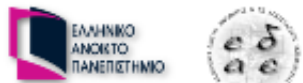

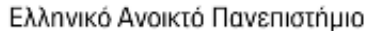

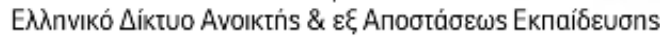

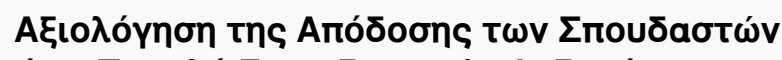

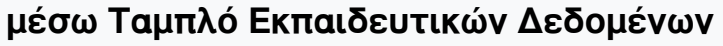

Andreas F. Gkontzis, Christoforos V. Karachristos, Fotis Lazarinis, Elias C. Stavropoulos, Vassilios S. Verykios

doi: $10.12681 /$ icodl.1096 


\title{
Assessing Student Performance by Learning Analytics Dashboards
}

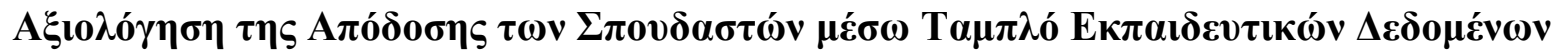

\author{
Andreas F. Gkontzis \\ $\mathrm{PhD}$ Candidate \\ School of Science and \\ Technology \\ Hellenic Open University \\ andreas.gkontzis@ac.eap.gr
}

\author{
Christoforos V. Karachristos \\ MSc \\ Educational Content, \\ Methodology \& Technology Laboratory \\ Hellenic Open University \\ karachrist@eap.gr
}

Fotis Lazarinis

$\mathrm{PhD}$

School of Science and

Technology

Hellenic Open University

fotis.lazarinis@ac.eap.gr

\author{
Elias C. Stavropoulos \\ $\mathrm{PhD}$ \\ Educational Content, \\ Methodology \& Technology Laboratory \\ Hellenic Open University \\ estavrop@eap.gr
}

\author{
Vassilios S. Verykios \\ Professor \\ School of Science and Technology \\ Hellenic Open University \\ verykios@eap.gr
}

\begin{abstract}
In today's competitive business environment, multiple diverse applications produce a huge amount of data, which are typically referred to as big data. Business Intelligence and Analytics are increasingly applied in public and private sectors for monitoring complex data using dashboards and effectively support decision making. Business dashboards (BDs), as complete executive information systems, enable business performance to be examined toward defined targets in a visual front-end interface. Institutions in distance learning apply similar methodologies to manage the explosion of educational data by employing data mining and visualization techniques in students' logs. The lack of a daily real-time data analysis and the delay in the immediate presentation of critical information, limit the teachers' early decisions. With the emergence of Learning Analytics Dashboards (LADs), as a system of collecting, analyzing and simultaneously visualizing vital knowledge in a customizable interface, teachers are provided with information regarding current students' progress. This study explores specific LADs in the Moodle platform, applied to a seminar offered by the Educational Content Methodology and Technology Laboratory of the Hellenic Open University and visualizes the findings of students' interactions. The papers' contribution concerns the enhancement of teacher decision-making and student self-reflection by monitoring their activity and providing accurate feedback on time.
\end{abstract}

Keywords: Learning Analytics Dashboards; Educational Data Mining; Distance Learning, Learning Management Systems; Moodle; Personalized Learning; Learning Assessment

\section{Пєрі́ $\eta \psi \eta$}

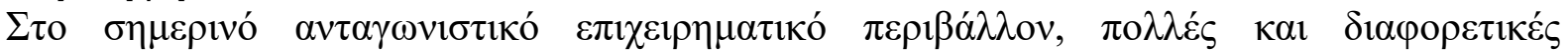

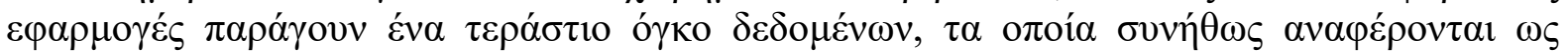

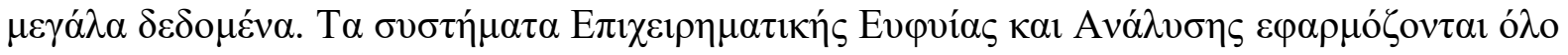

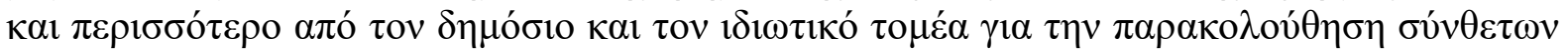

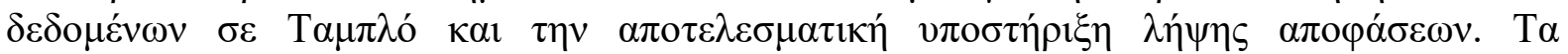

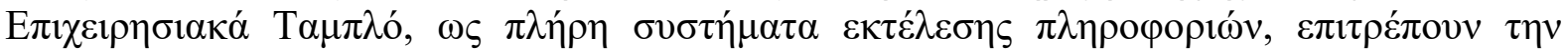




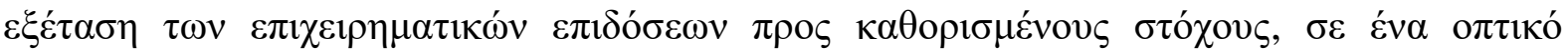

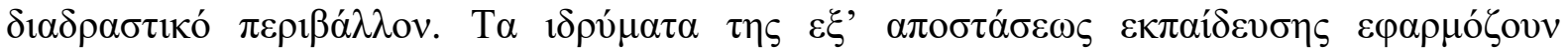

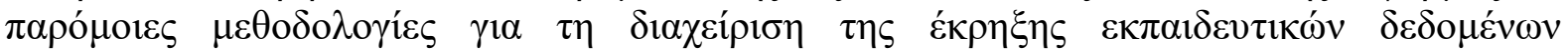

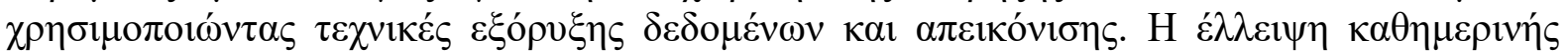

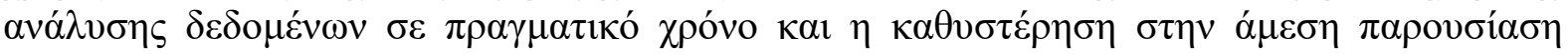

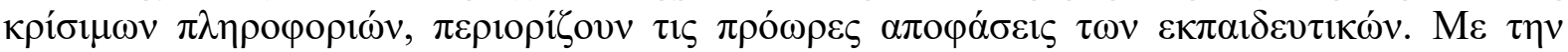
$\varepsilon \mu \varphi \alpha ́ v i \sigma \eta ~ \tau \omega v ~ T \alpha \mu \pi \lambda o ́ ~ A v \alpha ́ \lambda v \sigma \eta \varsigma ~ Е \kappa \pi \alpha ı \delta \varepsilon v \tau \imath \kappa \omega ́ v ~ \Delta \varepsilon \delta о \mu \varepsilon ́ v \omega v ~ \omega \varsigma ~ \varepsilon ́ v \alpha ~ \pi \lambda \eta ́ \rho \varepsilon \varsigma ~ \sigma u ́ \sigma \tau \eta \mu \alpha$

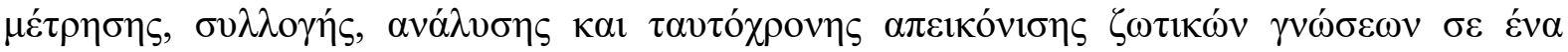

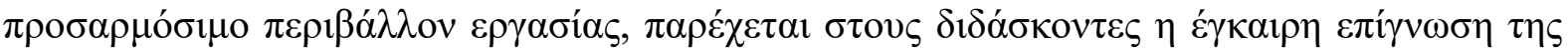

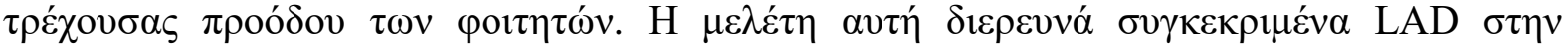

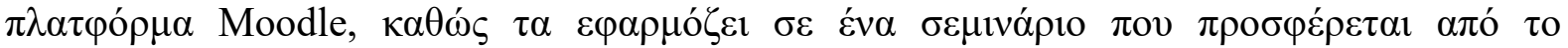

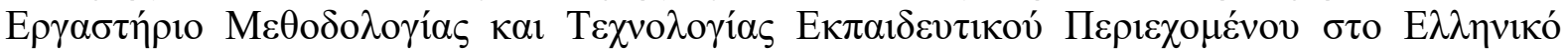

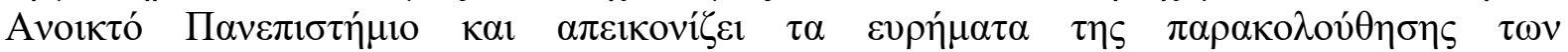

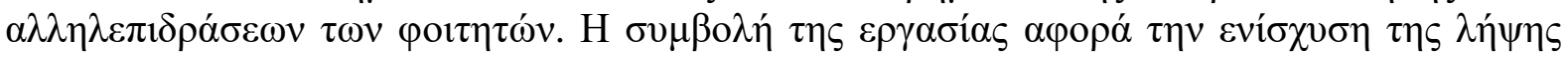

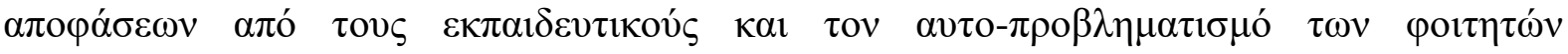

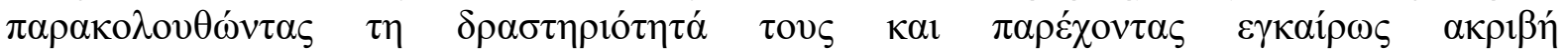
$\alpha v \alpha \tau \rho \circ \varphi о \delta o ́ \tau \eta \sigma \eta$.

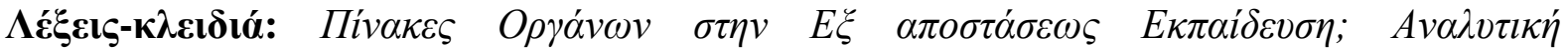

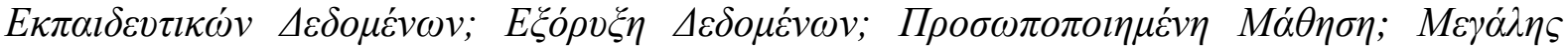

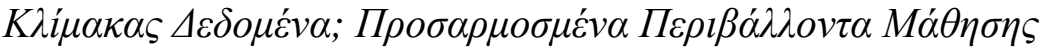

\section{Introduction}

For an increasing number of companies and organizations, it has become essential to implement large-scale automated analytics and monitoring functions, built into existing operational information systems, in order to manage the plethora of data on time. The need for deriving insights from the collected big datasets for fast and efficient business decisions is critical. Business intelligence and analytics are widely applied to measure performance, to identify patterns in the data, and present the hidden information in dashboards for turning data into actionable insights (Chiang et. al. 2012; Jones et al, 2016; Kessler, 2017). Business dashboards comprise a complete information management system, which track, analyze, and visualize metrics, key performance indicators (KPIs) and other key data values. By analyzing data in a timely manner and directly sending vital knowledge to a unified, highly interactive interface, BDs provide business professionals with the necessary guidance to improve their decision-making experience (Chiang et. al. 2012; Jones et al, 2016; Kessler, 2017; Konstantinidis \& Grafton, 2013; Yassine et al, 2016; Yool et al, 2015).

Inevitably, educational data analysis techniques have been applied to higher education for identification of meaningful information from large datasets. In recent years, Learning Management Systems (LMS) are increasingly used in higher education and established mostly for distance learning institutions. The widespread use of LMSs, creates a plethora of data that needs to be analyzed in real-time, so that the results must be visible on time to serve different purposes (Luna et al, 2017; Romero et al, 2013; Xiao et al, 2017; Yassine et al, 2016). Distance learning seeks to minimize the lack of students' physical presence in a classroom. Therefore, institutions of higher education continuously adopt new information technology for innovation and for staying ahead of the competition. As this development provide the opportunity to apply BI\&A techniques to big educational datasets, learning analytics (LA) emerged to highlight learners' status, interactions, activities and behaviors (Gasevic et al., 2015; Luna et al., 2017; Romero et al., 2013; Yassine et al., 2016; Yool et al., 2015). Within an LMS, LA techniques can analyze the large amount of educational data that 
have been produced by students' interactions and have been collected from the logging utility of the LMS. Simultaneously, another unit visualizes the analysis results on a dashboard, so it is possible for teachers to be informed at a glance for the learning progress of students. Learning Analytic Dashboard (LAD) by combining the benefit of these two worlds, enable at the same time real data analysis and timely visualization of educational knowledge. Thus, teachers can assess information and identify patterns that need to be explored (Conde et al., 2015; Gasevic et al., 2015; Kitto, et al., 2016; Sin \& Muthu, 2015; Verbet et al., 2013; Verbet et al., 2014; Yool et al., 2015). In contrast to the use of complexity of data extraction and analysis processes required by data mining techniques, the skills needed for using a LAD are not restricted to highly specialized knowledge and expertise (Conde et al., 2015; Liu et al., 2015; Jeonghyun et al., 2016; Yassine et al., 2016). For teachers, especially those with limited IT skills, it is imperative to adopt the LAD mechanism. By analyzing students' activities in real time and displaying information in a conceptual and meaningful way, they are able to make accurate decisions to avoid students' failure (Konstantinidis \& Grafton, 2013; West 2012). On the other hand, as students engage with LMS content, they become more familiar with the capabilities of LADs to visualize their own learning pace, for selfassessment and self-improvement. By providing real-time feedback on their own activity, students are able to comprehend their progress against the specific educational goals by helping them to personalize their learning experience. At the same time, they are informed on time about the risk of dropping out from a course and have the opportunity to improve their learning performance (Yassine et al., 2016; Sin et al., 2015; Verbet et al., 2013; Verbet et al., 2014; Liu et al., 2015; Jeonghyun et al., 2016; West et al., 2012).

Moodle is a popular open source LMS that is used by Hellenic Open University (HOU), to manage its training content and allow for communication and interaction among students and teachers. The system records students' status and various aspects of their activities through built-in tools. Until the time of this research, Moodle's visual reports are limited and there is a lack of flexibility to show students' vital interactions on a dashboard (Conde et al., 2015; Konstantinidis and Grafton, 2013; Liu et al., 2015; Yassine et al., 2016).

The aim of this work is to illuminate teachers with quick and effective feedback of student data paths for a visual programming seminar through the investigation of features offered by LADs. The proposed LADs are characterized by a friendly and interpretive environment that helps teachers with personalized intervention. Furthermore, we explore students' LAD, for optimizing their learning experience by tracking their own activities, to encourage selfassessment and promote awareness.

The rest of the paper is structured as follows: Section 2 provides an overview of the literature on data analytics in education and on LA. Sections 3 and 4 refers to the results of the application of the proposed LADs and comments on those. Finally, the last Section summarizes the main findings and address future work on this topic.

\section{Related work}

This section presents the relevant work in the field of educational data analysis, to support decision-making in education. Firstly, research studies on which scholars have performed an external analysis by downloading logs from LMS, in order to apply data mining and visualization techniques. Secondly, se present the relevant works that use LA within the LMS, for collecting, analyzing and visualizing the results in dashboards.

The opportunities and challenges of implementing data mining techniques in previously extracted LMS files, have been investigated by many researchers. Authors in Romero et al. (2013) proposed the use of different data mining approaches to LMS logs. Their aim was to improve the prediction of students' final performance based on their participation in an online discussion forum. They concluded that the use of data from the middle period of the 
course, has the potential to inform teachers about students at risk. However, the task of teachers to gather and extract data from students' online discussions is described as difficult and time-consuming. Authors in Konstantinidis et al., (2013) refer to a framework based on Excel macros and Visual Basic programming language, for downloading, analyzing, and visualizing the Moodle's log files. The offline mode of their method is probably a drawback. Lotsari et al., (2014) extracted forum messages from a postgraduate course module at Hellenic Open University (HOU) and analyzed logs by the statistical software R and the data mining toolkit WEKA. Although they have noticed that the final grade of the students is not correlated to their participation in the discussion forum, real-time analysis would have enriched the results. Moreover, Kaglis et al., (2015) extracted logs from online student fora of another course module at HOU, to identify trends, patterns and polarity among students' interactions by text mining techniques. They concluded that the polarity of the messages is not a powerful factor for predicting student performance. Similar to Lotsari et al., (2014), Kaglis et al., (2015) also concluded that forum participation is not an important factor for students' final performance. The lack of real-time analysis in Kaglis et al., (2015) also characterizes the recent work of Gkontzis et al. (2017). In Gkontzis et al. (2017), researchers downloaded fora logs for a course at HOU and proposed a framework consisting of a NoSQL system and the R software to identify students' emotions in on-line Moodle's discussions. Despite their obvious benefits, all the aforementioned methodologies are too complex for instructors to apply without a background in data mining and there is usually a delay in the monitoring of learning processes.

As Learning Analytics emerged to improve learner success, some researchers and higher institutions explored or designed their own LA tools by adding dashboards as an interface for immediate visualization of results analysis. Purdue University has created a learning indication for students to be warned on time for negative deviations from their learning goals. The use of LA has led the University to identify students' potential problems from the second week of the course and to improve students' attention (Uhler \& Hurn, 2013; Yassine et al., 2016). Petropoulou et al. (2014) presents an LA moodle assessment tool, called Learning Analytics Enhanced Rubric (LAe-R). It is about a blend of marking criteria and grading levels that are associated to traditional performance metrics, learning and interaction indicators, that LAe-R allows a teacher to add. Researchers' conclusions highlighted its advanced assessment features and specialized customization options, which were appreciated by teachers. Liu et al. (2015) presents a tool named Moodle Engagement Analytics Plugin (MEAP), to provide information about students' progress against a range of indicators. By enhancing the utility and impact of MEAP, they improved data visualizations and the quality of teachers' interventions. However, in Verbet et al., (2014) through their overview in learning analytics dashboards, conclude that despite the development on learning analytics dashboards, LA tools and applications are still at the starting point. Similarly, Yool et al., (2015) by evaluating ten popular educational dashboards, recognized the lack of resources and the need for further research on LAD process. In addition, Conde et al., (2015) in their qualitative analysis of Moodle' LA tools, highlight the necessity of adding LAD to the platform of Moodle for teachers simplicity in tracking students' progress. Furthermore, Molenaar and Campen (2016) in their experimental study, concluded in the necessity for advanced efforts to support teachers on how to use learning analytics.

\section{Moodle's Learning Analytics Dashboards}

As depicted in Figure 1, the process of learning analytics dashboards is to retrieve learners' data from the database (Student Data), calculate the corresponding evaluation indicators (Learning Analytics) and visualize real time results (Dashboard). 


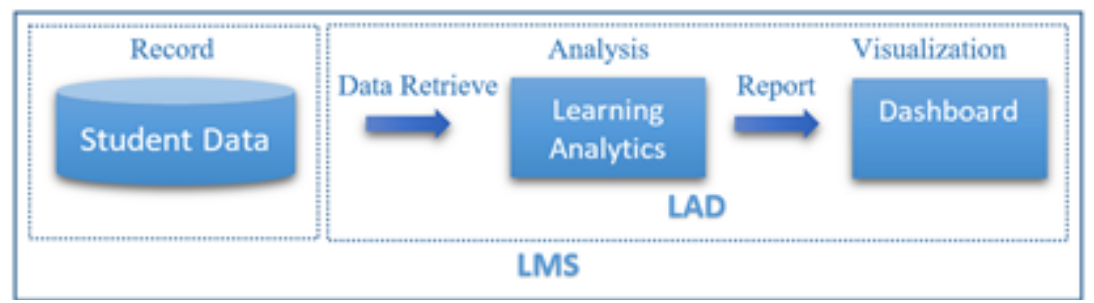

Figure 1. A representation of the LAD process.

In Figure 2 we report the most popular of them, as recorded on the Moodle-Open source learning platform, according to the version of the platform and the stakeholders. Our histogram is colored due to LADs download rate, during the last 90 days. We mention that some of them, like Intelliboard and SmartKlass, are third party plugins that one has to register to, and retrieve user personal data from Moodle platform.

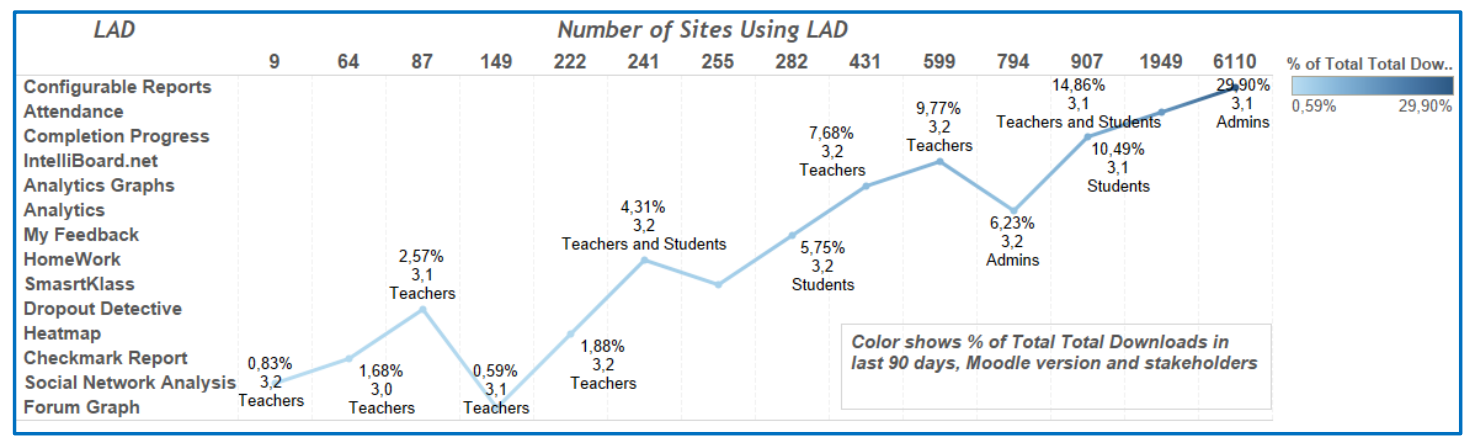

Figure 2. The most downloaded LADs, during the last 90 days.

In the sequel, we shortly present a number of selected LADs, that can be easily and effectively utilized by students, teachers and administrative staff and they do not emerge data privacy issues. More specifically, we refer to Completion Progress, Forum Graphs, Analytics Graphs, and Configurable Reports. The first one is suitable for both students and teachers, the next two are for teachers, and the last one allows administrators to create custom reports and make them available only to end users. The selected LADs are demonstrated in the next section, through the analysis of data from our case study.

\subsection{Completion Progress}

The Completion Progress block (Blocks: Completion Progress) is a color-coded progress bar for students and teachers. It visually presents the activities and resources with which the student is expected to interact in a course, based on the course requirements. Different colors indicate the activities and resources that students have or have not completed or viewed. The green color corresponds to completed activities or resources while blue color to future notcompleted ones. There also exists the yellow color for the submitted but not completed ones, and the red color for the non-completed ones. The ordering of the activities and resources can be based on expected completion times or on the ordering of activities in the course. The progress bar and the colors are customizable.

\subsection{Forum Graph}

The Forum Graph Report (Reports: Forum Graph) processes data from a single forum activity in a course, analyze the interactions between students and teachers and create a directed graph. Nodes represent participants, colored with different colors for teachers and students, while edges represent the interaction among the participants. The size of each node 
depends on the number of messages the participant posted, while the thickness of an edge indicates the number of replies and the arrow defines who was replying.

\subsection{Analytics Graphs}

The Analytics Graphs block (Blocks: Analytics Graphs) is a descriptive tool that provides numerus graphs that can be used to facilitate the identification of students' profile, in order a teacher to make the right decisions and enhance the teaching process. By clicking on a graph element, the teacher can immediately communicate with a student or a group of students, according to their performance, by sending an email to them. The Analytics Graph block could be used in the first weeks of a course to increase student study engagement and consequently to reduce dropout rates.

\subsection{Configurable Reports}

Configurable Reports block (Blocks: Configurable Reports) is a custom report builder, appropriate for administrators or teachers to create reports. Reports are customized using SQL queries and can be viewed by selected users. Non-expert users, like teachers, can easily create some kind of reports, however for more complex information, knowledge of Moodle database schema along with an expertise on design and development SQL queries is required. Moreover, developers can create new plugins with new types of reports. In Figure 3 we show the available tabs when creating a new SQL report. Categories reports, Course reports, Timeline reports, and Users reports are also available.

View report Custom SQL Filters Template Permissions Calculations Plot-Graphs
Report Manage reports

Figure 3. The SQL query tabs available on Configurable Reports block

\section{Case Study}

In this section, we present a case study conducted within a blended learning course under program "Design and implementation of a blended learning course on visual programming: Code - Create - Learn with Scratch" (E-Comet Lab, 2016), implemented by the Educational Content, Methodology \& Technology Laboratory (E-Comet Lab) of the Hellenic Open University, and funded by the Stavros Niarchos Foundation.

Scratch is a visual programming environment, developed by MIT (Scratch), which is suitable for introducing programming to novice users. Applications are built by combining visual blocks. Each visual block facilitates a specific type of user-computer interaction and by thorough combination, powerful game like applications can be developed. During this process users are able to comprehend the basic programming concepts and develop transferable software design skills. Scratch has been used extensively in introductory programming courses Kaucic \& Asic, 2011; Meerbaum-Salant, Armoni, Ben-Ari, 2013).

Based on the above observations, we created a blended learning course for aiding teachers to acquire basic programming skills. The course it structured in seven units. In each unit, specific learning goals are set and is further divided into sections. In each section, the functions of specific visual blocks are explained using a textual description and a video presentation. Then through a number of step-by-step examples we provide a careful explanation of example code. The covered example programs show how to use and combine visual blocks to create small animated stories. Finally, at the end each of each section users are asked to develop short applications to test their knowledge. At the end of each unit, trainees have to take multiple choice tests which require interaction with the programming environment. These tests present short sequences of visual blocks and the users have to 
actually re-create and run them in order to be able to choose the correct answer. All-in-all the participants have to build a lot of block sequences in each unit which helps them to understand not only the function of each block but the art of combining them intelligently in order to create larger applications, i.e. to understand what programming is really about.

MOOCs usually have low completion rates and correlate negatively with course length (Clow, 2013; Jordan, 2014; Hone \& El Said, 2016). Therefore, we preferred a blended learning approach. The course was divided into four teaching cycles. In each cycle, we aimed to have approximately 150 participants from different cities of the same province. All the participants were teachers in schools or they could potentially work as teachers. At the beginning of the course live sessions with up to 20 of the participants were held in different cities of the province to explain the goals, the teaching model, the course requirements and in general to answer all the questions of the participants. In this mode, the participants were more prepared for the course, felt less anxious and knew that they could get assistance if it was required. During the course, peers and tutors replied to the forum questions which was another method for reducing the burden of the trainees, encouraging them to continue working on the course.

Each unit had to be completed in one week, except the last one, that had to be completed in two weeks. During the first week, i.e. the first unit, online students had to complete a questionnaire surveying their knowledge and their expectations, and they were introduced to the Scratch environment and to the concept of programming in general. During the next weeks, the participants immersed more into the programming techniques and the workload has been gradually increased. In the seventh (two week) unit, the trainees had to finish all pending activities from previous weeks and to complete a short assignment concerning the development of a short game for educational purposes.

To support the learning process, a Moodle v.3.2 was installed on an Ubuntu Server 16.04.1, with 4 processors at 2.6GHz, having 2GB RAM and 80GB HDD (Scratch Coding). For each cycle, a Moodle course was developed, and the users' accounts for the participants were created (860 learners in total). Next, the plugins described in Section 4 were installed, tested and evaluated on these courses. In the sequel, we give some screenshots and discuss the outcome of the evaluation. To preserve anonymity, all data that could be used to identify students' personal information have been erased.

\subsection{Completion Progress}

A student's standard view of the completion progress is shown in Figure 4. By taking a quick look, a student can have an overview of his/her progress and manage his/her time. In our example, a student can immediately find out that an activity is not completed (the corresponding cell is not colored blue), by pointing on it can have a small piece of information about this activity. By clicking on it, s/he can be directed to the activity submission page.

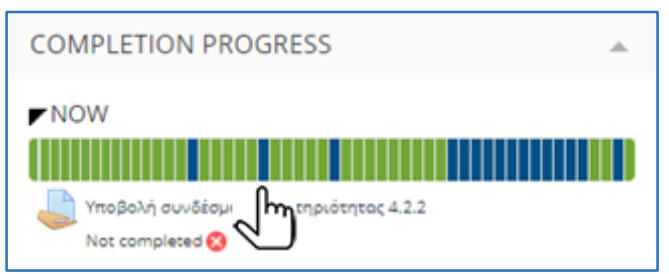

Figure 4. A Completion Progress bar for a student

Additionally, the Completion Progress block offers an overview page that allows teachers to see the progress of all students in the course (see an example in Figure 5). The teacher can identify students at high risk to miss the course or to drop out, and focus on them by offering extra care and guidance to overcome the learning difficulties and obstacles, and encourage 
them to keep on. Moreover, the teacher can identify, congratulate and reward students that respond promptly and cope successfully with the requirements of the course.

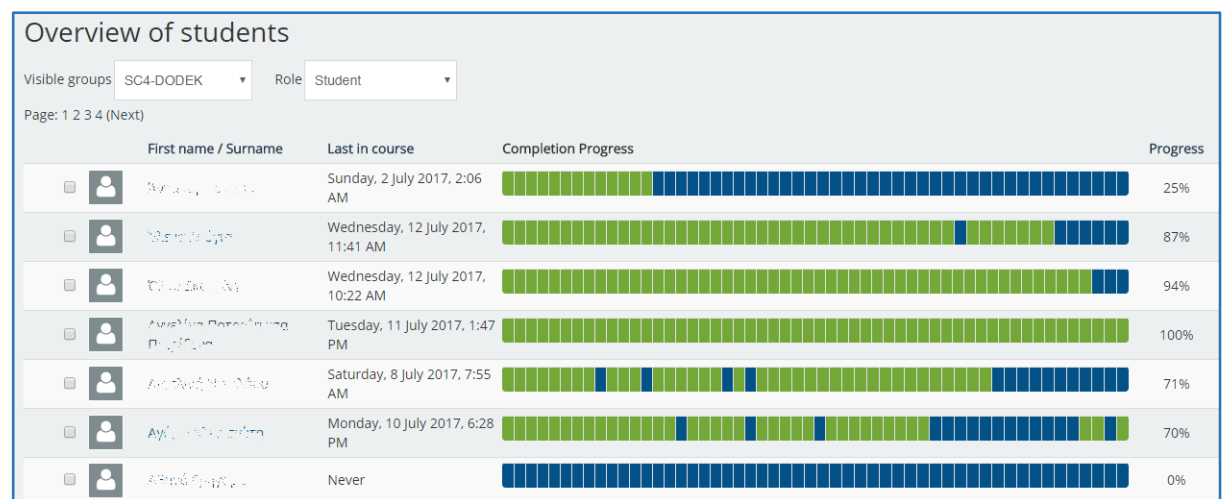

Figure 5. An overview page that shows the progress of all students in a course

By clicking on the profile image or on his/her name, the teacher can be directed to the student's profile information page and next see his/her daily or overall activity that is recorded on Moodle's log files (see Figure 6). Moreover, the teacher can easily have more findings for a particular student by looking at the dashboards described in the next sections, and thus obtain a more global picture for student's performance. In addition, he can identify activities that are not completed are resources that are not accessed by the majority of the students. Thus, the Completion Progress dashboard may act as an indicator for evaluating the educational content of the course, by indicating assignments of high difficulty of educational material of low quality.
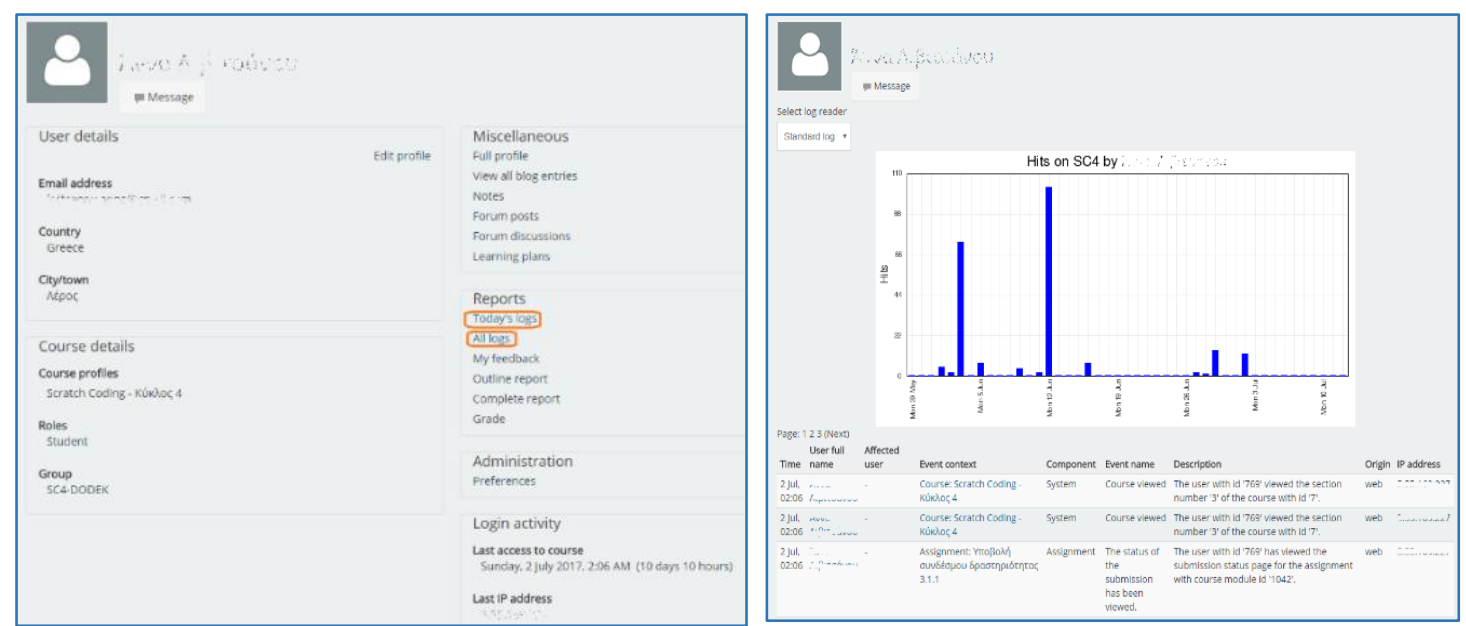

Figure 6. The profile information page (on the left) where teacher can access students' log files and have an overview of their daily hits and activities (on the right)

\subsection{Forum Graph}

In Figure 7 (left side) we give an example of a forum graph created by the activity of a weekly standard forum for general use, where students post questions and teachers answer on them. We can notice two active teachers (the big orange nodes) responding to students' requests. Nodes are draggable and these is an option for displaying or not the participants full names (to preserve anonymity, we have chosen to hide them). On the right side of Figure 7, we give the forum graph created by the posts of the students' peer reviewing their assignments. A few teacher posts exist, and a small number of answers to every assignment were posted. 

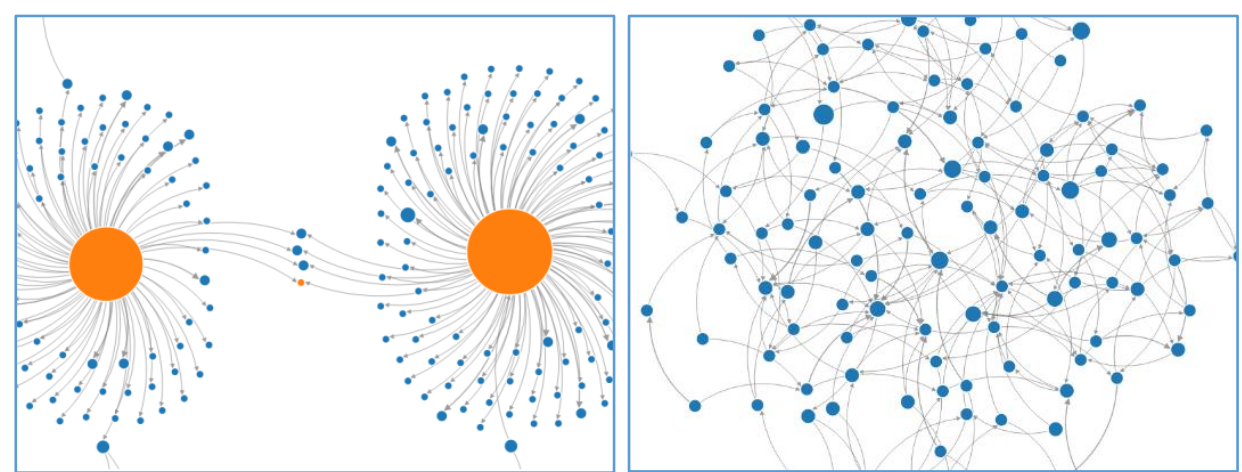

Figure 7. Forum graph report depicting the activity of students and teachers in a weekly forum (on the left) and the activity among students in a peered reviewed assignment (on the right)

By placing the cursor on a node, a tooltip shows the participant full name, the number of discussions and number of responses. For example, in Figure 8, a student created three discussions and answered once. If a teacher clicks on the node, a new window pop-up showing the log with the complete activity of the student in the forum. In this way, teachers can seek further information and communicate with their students.

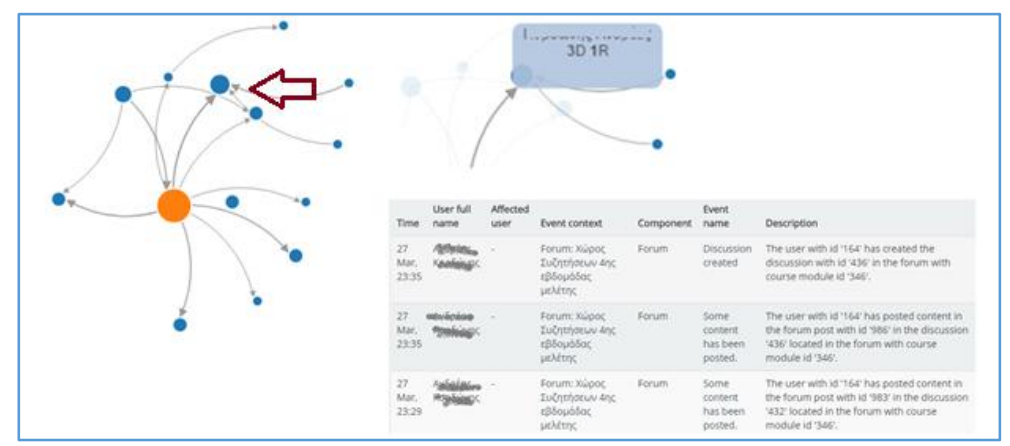

Figure 8. The available information by pointing or clicking a node of a forum graph

Forum graph reports provide teachers with a quick view of students' activity, interaction, and participation to a course forum. Forum participation may not be an index for predicting students' final grades (Kaglis et al., 2015), however it is an indication that suggests students who are struggling to keep up with the course. A node in the forum graph like the left one in Figure 9, indicates an inactive student that probably has no interest to keep up with and succeed in the course. The teacher can combine this information with student's progress depicted in the Completion Progress dashboard, and provide extra help and support to him. On the contrary, a student with a satisfactory number of posts and replies in the forum, like the one in right Figure 9, seems to be engaged in the course and less attention is needed by his teacher.
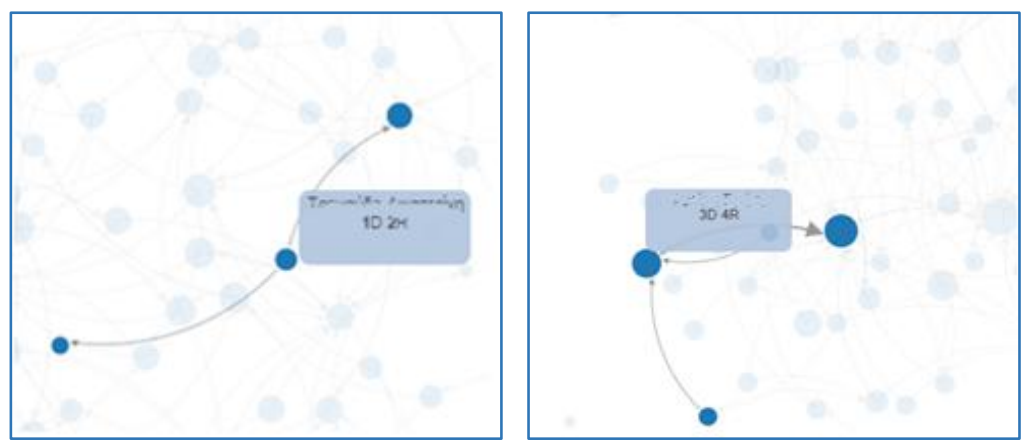

Figure 9. An examples of a less active student (on the left) and a more active student (on the right) in a forum graph report 


\subsection{Analytics Graphs}

In Figure 10 there is a grades chart, for a number of assignments of the course we study. When clicking on a boxplot, a new window pops-up giving a more information about the number of students with grades into the $25^{\text {th }}$, the $50^{\text {th }}$, and the $75^{\text {th }}$ percentile. The teacher can next communicate with each group of students, directly, by clicking on the corresponding link (see an example in Figure 11), provide them with feedback, assess, and encourage them to keep on. Providing grades and feedback on students' work is critical for increasing the active participation of the students, engaging the students with the learning environment and with the learning material.

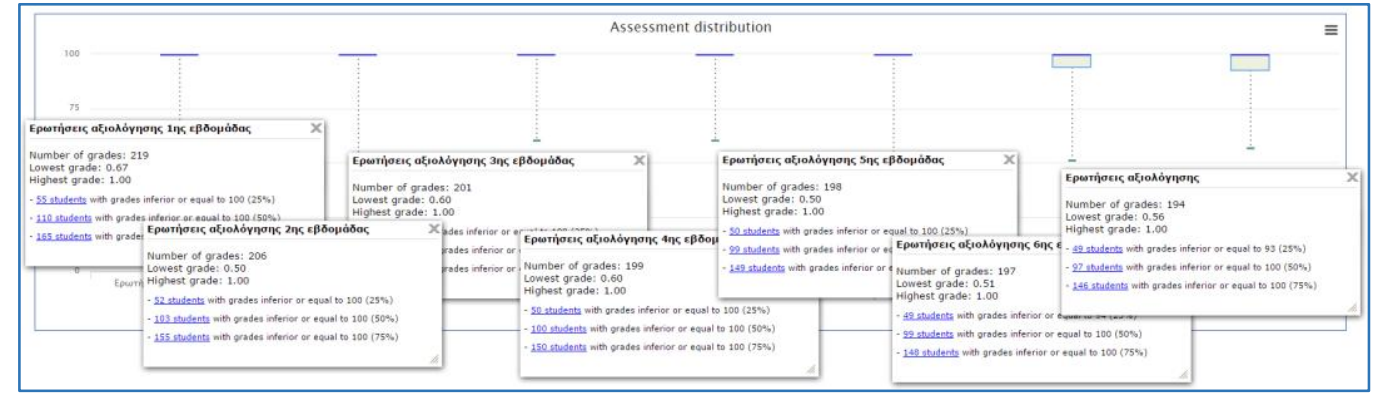

Figure 10. The grades distribution for selected assignments from a course

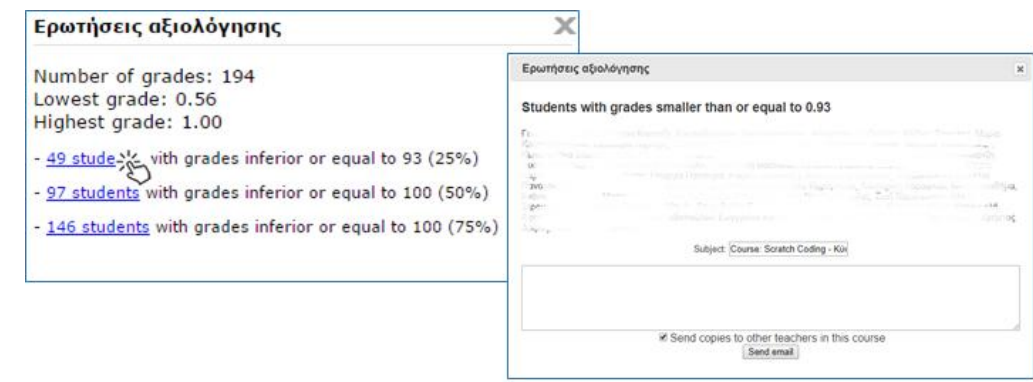

Figure 11. Communication with the group of students with grades in the $25^{\text {th }}$ percentile

An example of Content Access is given in Figure 12. The chart contains a part of activities and resources of our course. Clicking on the bar lists students by name and allow the teacher to send a massive message to them. Prior to an important deadline, a teacher can use this chart to control which of the students have not looked at a given assignment or quiz and remind them of the upcoming deadline. Moreover, a teacher can use the chart to contact with students who have not visited a forum or never accessed a certain educational material (text or video). In a course with a linear, chronological set up of activities and resources, the content access chart can address the students that are engaging with the material and those who are lagging behind for tutoring.

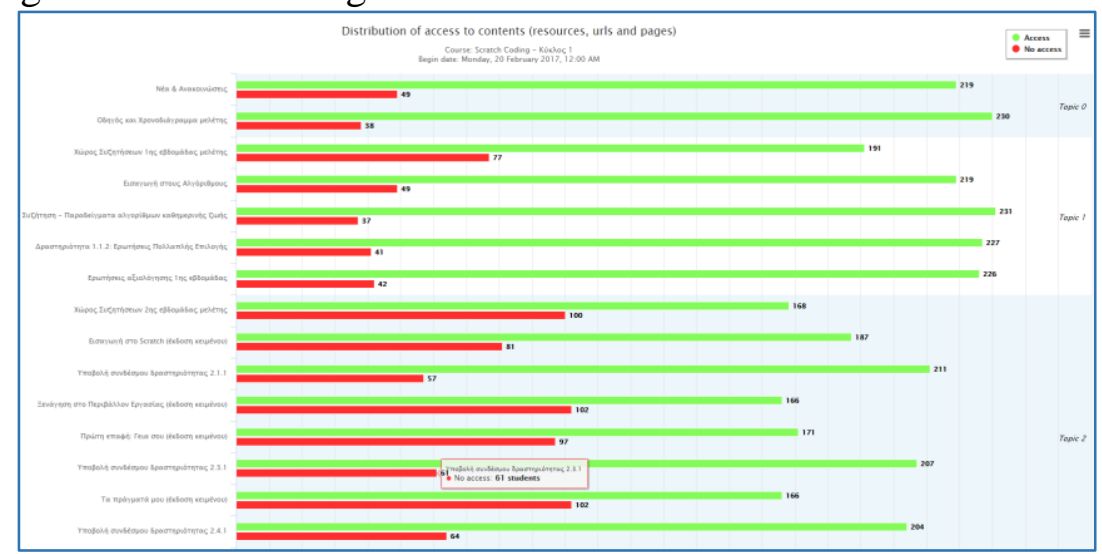

Figure 12. An example of a content access chart 
Activity Users charts are shown in Figure 13. The left one shows the number of active students during the day while the second one shows the number of students' activities. By clicking on a bar of the chart, a pup up window shows the names of students along with the activities that were dealt with, in the specific time of day. These charts provide the teacher with an impression of the more active and productive hours during a day and can timeschedule, for example, a teleconference session, late in the evening rather than early in the morning, so that the majority of the students to be able to attend.

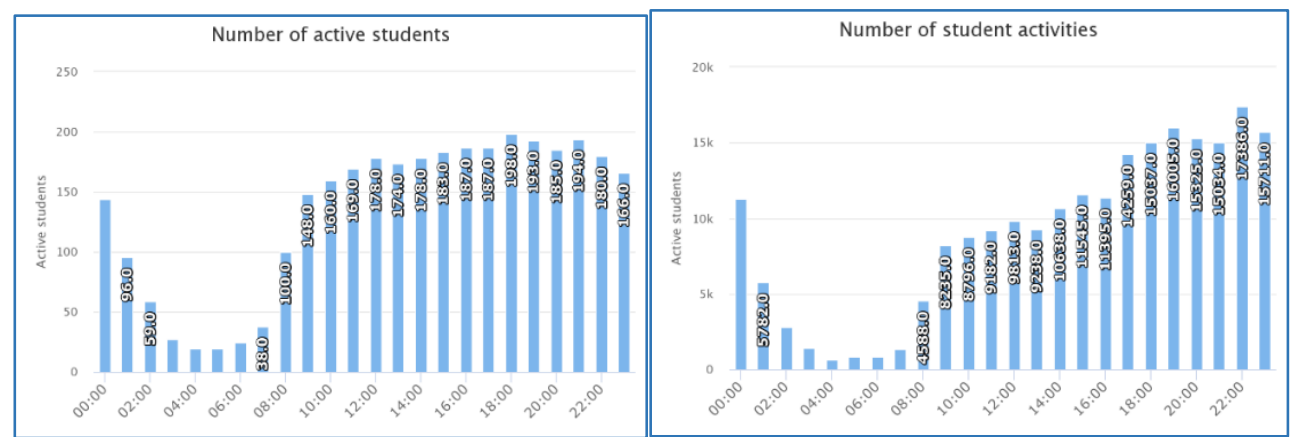

Figure 13. The distribution of active students (left) and students' activities (on the right)

Examples of Assignment and Quiz Submission Charts are shown in Figure 14. Submission Charts can be useful in a course with many assignments and/or quizzes, gradually placed in the learning process, in order for the teacher to have an understanding of students' participation, and to influence them to keep on.
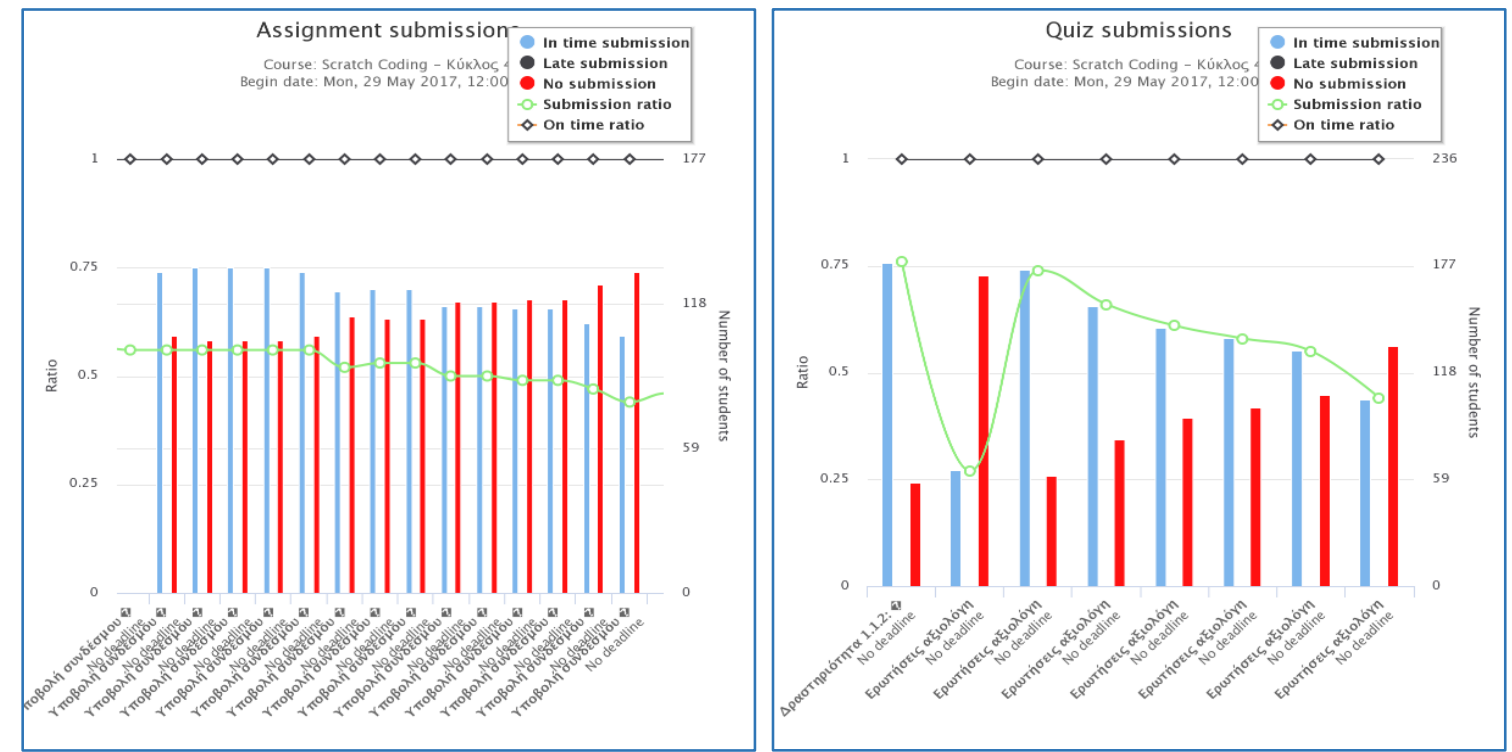

Figure 14. Assignment and Quiz Submission Graphs

In Figure 15 we give an example of a Hits Distribution Chart. When the teacher clicks a student name, a pup-up window appears containing tabs with a versatile of information. The teacher can compose and sent a new message to the student, or have an overview of messages sent to the student before. Moreover, pie charts containing information about the student's access of course contents, assignments and quizzes submissions, and forum participation (see an example in Figure 16). Clicking these pie charts, teacher will list the applicable data and all charts can be printed or exported. 


\begin{tabular}{|c|c|c|c|c|c|c|c|c|}
\hline \multicolumn{9}{|c|}{$\begin{array}{c}\text { Hits distribution } \\
\text { Course: Scratch Coding - Kúki..0 } 4 \\
\text { Begin date: Mon, 29 May 2017, 12:00 AM }\end{array}$} \\
\hline \multicolumn{4}{|c|}{ Students } & $\begin{array}{l}\text { Course } \\
\text { hits }\end{array}$ & $\begin{array}{l}\text { Days } \\
\text { with } \\
\text { access }\end{array}$ & $\begin{array}{l}\text { Number of days by week with access } \\
\text { (Number of neeks: } 7)\end{array}$ & $\begin{array}{l}\text { Resources } \\
\text { with } \\
\text { access }\end{array}$ & Number of resources accessed by week \\
\hline- & $\because \ldots A$ & s & & 157 & 13 & $\frac{}{1}$ & 32 & ${ }_{.}$ \\
\hline \multirow[t]{2}{*}{.-} & . & , & $\Lambda$ & 12 & 4 & . $\ldots$ & 3 & . \\
\hline & $-m \pi \cdot$ & $1=$ & $\triangle$ & 6 & 1 & $\frac{}{1+1} \cdots$ & 2 & . \\
\hline $\mathrm{K}$ & $\rightarrow-$ & in & $\triangle$ & 22 & 4 & . & 15 & $\stackrel{\mathrm{m}}{\longrightarrow}$ \\
\hline$\cdots \cdots$ & T. & $\cdots$ & & 207 & 24 & . & 27 & . \\
\hline ate & $\cdots$ & & $\Delta$ & 3 & 1 & $\ldots$ & 0 & \\
\hline
\end{tabular}

Figure 15. The hits distribution chart
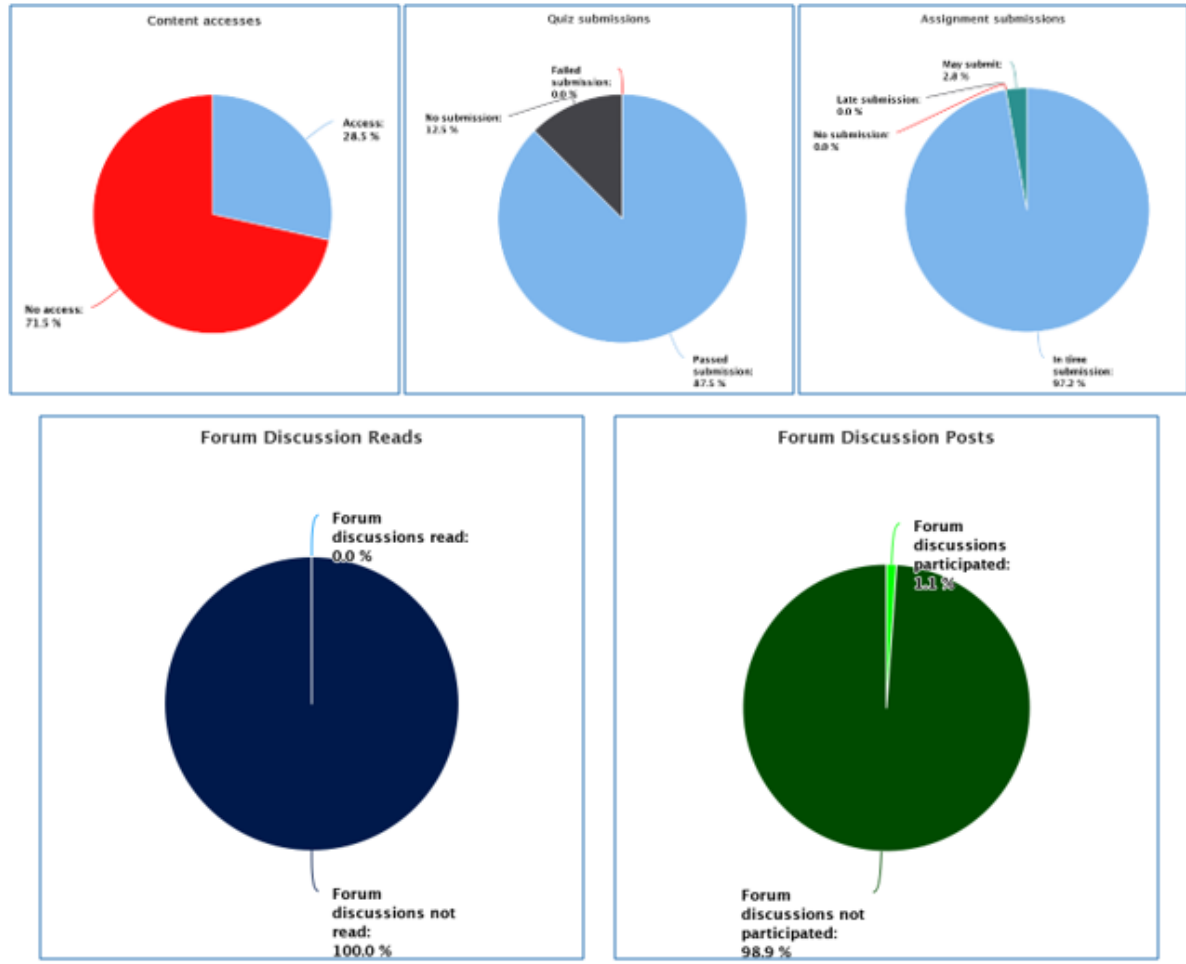

Figure 16. Activity charts for a particular student

The Hits Distribution Chart is useful when the resources are evenly distributed in every week of the course, and are weekly available to the student. It can monitor who students are engaged with the content of the course and facilitate the teacher to point out students that possibly will or have dropped out. 


\subsection{Configurable Reports}

Configurable Reports are the most demanding to be implemented, since they are suitable mostly for administrators. In Figure 17 we give the outcome of a customized report developed by SQL. Each bar in the chart corresponds to a course and the number of enrolled students appears on the top of it. A pie chart shows the percentage of enrolled students in all courses in total. By clicking on the "Show Users" link, the user is directed to the course participant page.

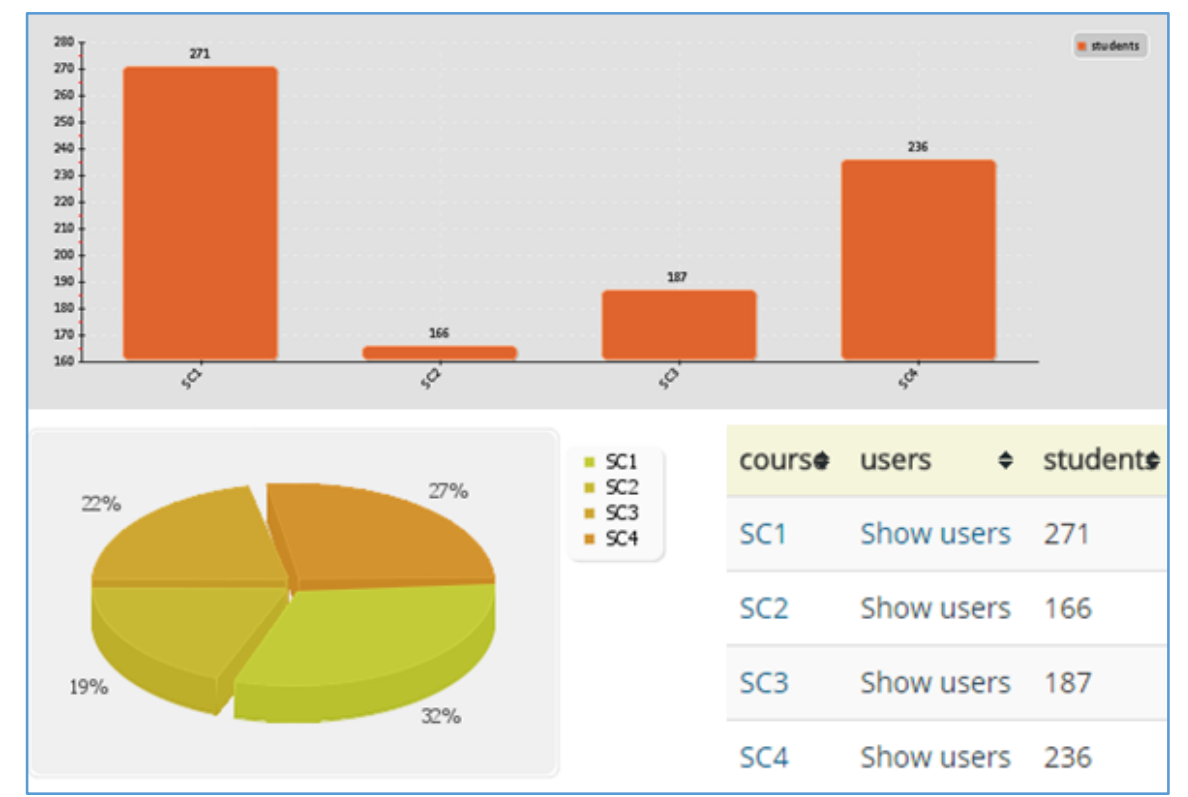

Figure 17. An example of Configurable Reports, showing students' enrollment

\section{Conclusions and future work}

This project has provided real time approaches to assess critical issues in education, such as student progression and retention for personalized and adaptive learning. This study explores the ecosystem of specific LADs to support Moodle teachers by effectively identifying student interactions. The implementation of the selected LADs presents how teachers can facilitate and rely on timely feedback to obtain an overview of student engagement and progress in different contents. The proposed framework is applied to the Moodle platform used in a blended learning course, implemented by e-CoMeT Lab of the Hellenic Open University. The analysis and monitoring process of student's logs take place inside the platform, helping teachers with a lack of learning analytics methodology, to highlight student's weaknesses and deficiencies. In order to increasingly clear the importance of educational data, this document evaluates the LADs process from the end users' point of view, focusing on visualizing student participation in various activities in the course.

The analysis of educational data shows that teachers have the ability to track educational trends online, as the learning process evolves and to provide more personalized guidance to students according to their behavior during the course. In addition, students are able to follow their current educational status in the course, enhancing self-assessment and selfimprovement. While the results of the study are promising, further investigations should be undertaken to address the limitations of this document. We propose an analysis of the effectiveness and usefulness of our research in a range of courses to identify students at risk, according to non-completion and fail rate in assessments. Also, it would be indispensable to collect people opinions who have involved in the preferred process, so that their empirical thoughts would lead to re-evaluations and improvements with a positive impact on learning. 
Furthermore, the effective cooperation of stakeholders in LMS is crucial, for penetrating data quality and providing high educational services to students.

\section{Acknowledgements}

Research was funded by the Stavros Niarchos Foundation under program "Design and implementation of a blended learning course on visual programming: Code - Create - Learn with Scratch" of the e-CoMeT Lab / HOU, Greece, and by a Google RISE award.

\section{References}

Blocks: Analytics Graphs. Retrieved from https://moodle.org/plugins/block_analytics_graphs

Blocks: Completion Progress. Retrieved from https://moodle.org/plugins/block_completion_progress

Blocks: Configurable Reports. Retrieved from https://moodle.org/plugins/block_configurable_reports

Chiang R.H.L., Goes P., Stohr E.A. (2012). Business intelligence and analytics education, and program development: A unique opportunity for the information systems discipline. ACM Transactions on Management Information Systems, 3, pp. 12-24.

Clow, D. (2013). MOOCs and the funnel of participation. In: Third Conference on Learning Analytics and Knowledge (LAK 2013), 8-12, Leuven, Belgium, 185-189. doi:2460296.2460332

Conde, M. A., Hérnandez-García, A., García-Peñalvo, F. J. \& Séin-Echaluce, M. L. (2015), Exploring Student Interactions: Learning Analytics Tools for Student Tracking. In Learning and Collaboration Technologies, 50-61.

E-Comet Lab. (2016). Scratch Coding. Retrieved from http://scratchcoding.eap.gr

E-Comet Lab. Retrieved from http://eeyem.eap.gr/en/home/

Gasevic D., Dawson S. \& Siemens G. (2015). Let's not forget: Learning analytics are about learning. Association for Educational Communications and Technology, 59(1), 64-71.

Gkontzis A.F., Karachristos C., Panagiotakopoulos C. T., Stavropoulos E.C. \& Verykios V. S. (2017). Sentiment Analysis to Track Emotion and Polarity in Student Fora. In Proceedings of the 21st PanHellenic Conference on Informatics, Sep 28-30, 2017 - Larisa, Greece

Hone K.S. \& El Said G.R. (2016). Exploring the factors affecting MOOC retention, a survey study. Computers \& Education, 98, 157-168. doi:10.1016/j.compedu.2016.03.016

Jeonghyun K. \& IL-Hyun J. (2016). Effects of learning analytics dashboard: analyzing the relations among dashboard utilization, satisfaction, and learning achievement. Asia Pacific Education Review, 17, 1324.

Jones St., Cournane S., Sheehy N. \& Hederman L. (2016). A business Analytics Software Tool for Monitoring and Predicting Radiology Throughput Performance. Journal of Digiting Imagine, 29, 645-653.

Jordan, K. (2014). Initial trends in enrolment and completion of massive open online courses. The International Review of Research in Open and Distance Learning, 15, 1. doi: 10.19173/irrodl.v15i1.1651

Kagklis V., Karatrantou A., Tantoula M., Panagiotakopoulos C.T., \& Verykios V.S (2015). A Learning analytics methodology for detecting sentiment in student fora: A case study in distance education. European Journal of Open, Distance and E-learning, 18 (2),74-94.

Kaucic, B., Asic, T., (2011) Improving introductory programming with Scratch?," in IEEE MIPRO, 2011 Proceedings of the 34th International Convention, 1095-1100.

Kessler R.W. (2017). Process analytics in science and industry. Analytical and Bioanalytical Chemistry, 409, 629-630.

Kitto K., Lupton M., Davis K. \& Waters K. (2016, November 28-30). Incorporating Student-Facing Learning Analytics into Pedagogical Practice. In Proceedings of the 33rd Annual ASCILITE Conference (Ascilite16). Adelaide, S.A., Australia.

Konstantinidis A. \& Grafton C. (2013, October, 4-5). Using Excel Macros to Analyze Moodle Logs. 2nd Moodle Research Conference (MRC2013), 33-39, Souse, Tunisia.

Liu D.Y.T., Froissard J-C., Richards D. \& Atif A. (2015). An enhanced learning analytics plugin for Moodle: student engagement and personalized intervention. In Proceedings of the 32nd Conference of the Australasian Society for Computers in Learning in Tertiary Education, Perth.

Lotsari El., Verykios V.S., Panagiotakopoulos C., \& Kalles D. (2014). A Learning Analytics Methodology for Student Profiling. Hellenic Conference on Artificial Intelligence, 300-312.

Luna J.M., Castro C., Romero C. (2017). MDM Tool: A Data Mining Framework Integrated Into. Moodle. Computer Applications in Engineering Education, 25 (1), 90-102, 2017. doi:10.1002/cae.21782. 
Meerbaum-Salant, O., Armoni, M., Ben-Ari, M. (2013). Learning computer science concepts with Scratch, Computer Science Education, 23(3), 239-264. doi:10.1080/08993408.2013.832022

Molenaar I. \& Campen C. K.V. (2016) Learning Analytics in Practice. The Effects of Adaptive Educational Technology Snappet on Students' Arithmetic Skills. LAK '16, 538-539.

Petropoulou O., Kasimatis K., Dimopoulos I. \& Retalis S. (2014). LAe-R: A New Learning Analytics Tool in Moodle for Assessing Students' Performance. IEEE Technical Committee on Learning Technology, $16(1), 2-5$.

Moodle-Open source learning platform. Retrieved from https://moodle.org/

Reports: Forum Graph. Retrieved from https://moodle.org/plugins/report_forumgraph

Romero C., López M.I., Luna J.M. \& Ventura S. (2013). Predicting students' final performance from participation in on-line discussion forums. Computers \& Education, 68, 458-472.

Scratch. Retrieved from https://scratch.mit.edu/

Scratch Coding. Retrieved from http://scratchcoding.eap.gr/platform/

Sin K.and Muthu L. (2015). Application of Big Data in Education Data Mining and Learning Analytics- A Literature Review. ICTACT Journal of Soft Computing: Special Issue on Soft Computing Models for Big Data, 05(04), 1035-1049.

Uhler B. D. \& Hurn J. E. (2013). Using Learning Analytics to Predict (and Improve) Student Success: A Faculty Perspective. Journal of Interactive Online Learning, 12(1), 1541- 4914.

Verbet K., Duval E., Klerkx J., Govaerts S. \& Santos, J. L. (2013). Learning Analytics Dashboard Applications. American Behavioral Scientist, 57 (10), 1500-1509.

Verbet K., Govaerts S, Duval E., Santos J. L., Assche F. V., Parra G. \& Klerkx J. (2014). Learning dashboards: an overview and future research opportunities. Personal and Ubiquitous Computing, 18, 1499-1514.

West, D. M. (2012). Big data for education: Data mining, data analytics, and web dashboards. Governance Studies. Washington, DC: Brookings Institute.

Xiao H., Hou X., Lei C.U., Chengrui Y. \& Jeremy N. (2017). An Outcome-based Dashboard for Moodle and Open EdX. Proceedings of the Seventh International Learning Analytics \& Knowledge Conference, 604-605. doi:10.1145/3027385.3029483.

Yassine S. \& Kardy S. (2016). A Framework for Learning Analytics in Moodle for Assessing Course Outcomes. IEEE Global Engineering Education Conference (EDUCON), Abu Dhabi, 261-266.

Yool Y., Lee H., Jo, I. H. \& Park Y. (2015). Educational Dashboards for Smart Learning: Review of Case Study. Emerging Issues in Smart Learning, 145-155. 